\title{
Correction to: K-Schedules Meet Precision Measurement: A Protocol for Intervention
}

\section{Kerri Milyko $^{1}$}

Published online: 1 October 2020

(C) Association for Behavior Analysis International 2020

\section{Correction to: Behav Analysis Practice} https://doi.org/10.1007/s40617-020-00459-2

This article was updated to correct Figures 4 and 5, which were initially published as duplicates of Figure 2. 


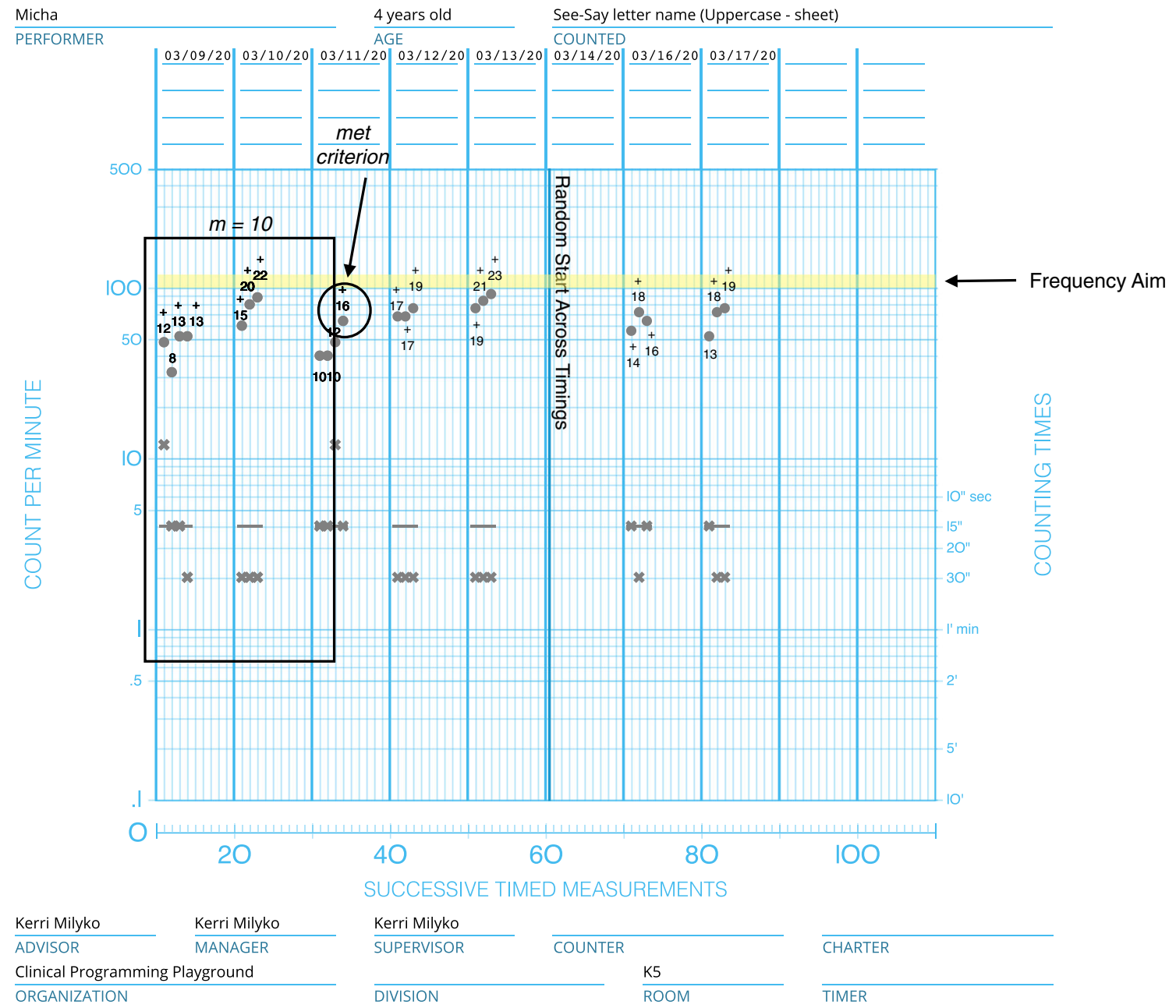

Fig. 4 Similar to Fig. 2, with highlighting to show the "recent" timing that met the specific criteria 


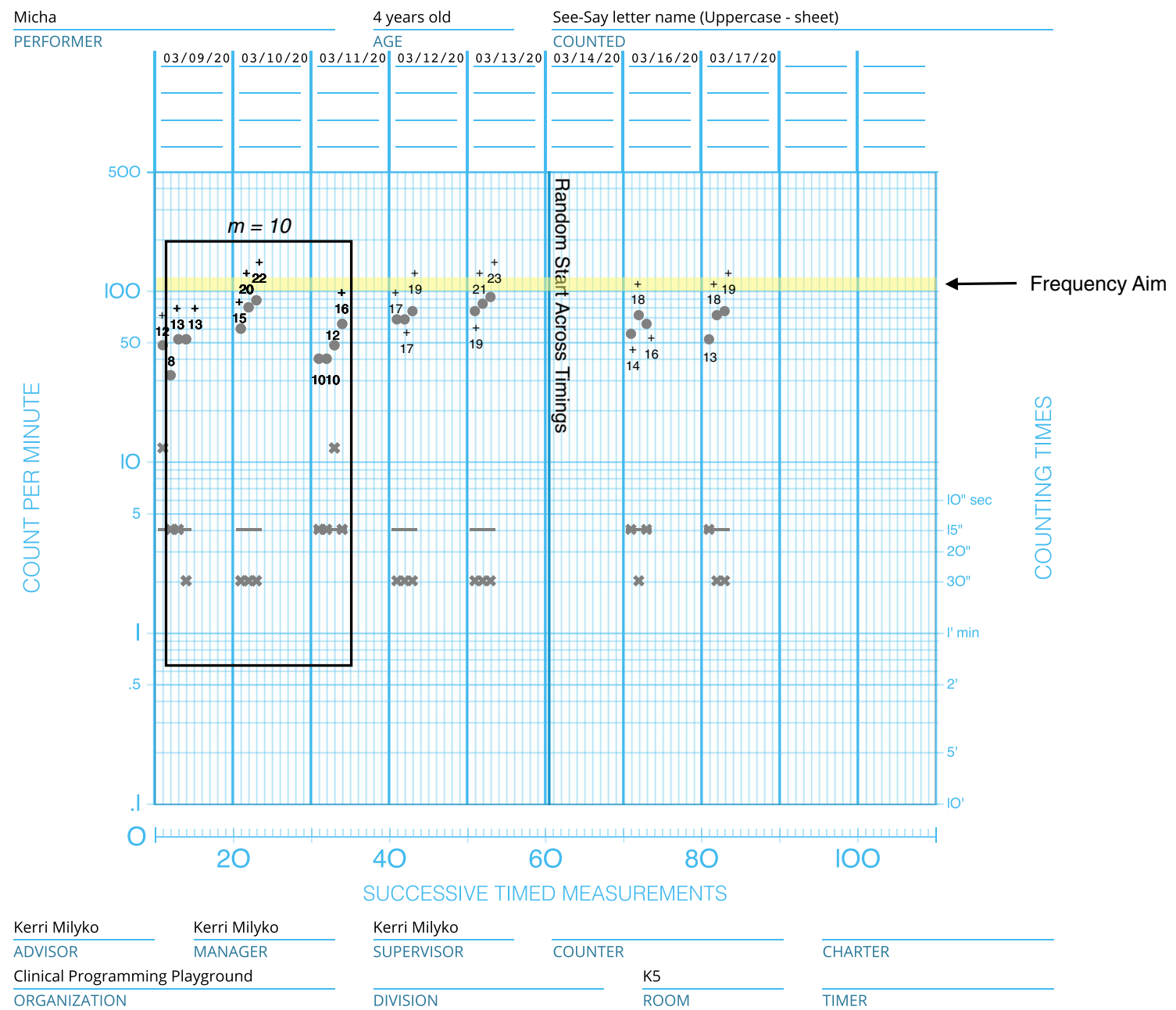

Fig. 5 Similar to Fig. 4, but shifting the $m=10$ window to include themost recent timing. Therefore, the old timing is removed fromthe window to allow the new timing to be included in the calculation of the specific criterion 